This item was submitted to Loughborough's Research Repository by the author.

Items in Figshare are protected by copyright, with all rights reserved, unless otherwise indicated.

\title{
Validation of the HADRIAN system with a train station design case study
}

PLEASE CITE THE PUBLISHED VERSION

http://dx.doi.org/10.1201/9780203872512.ch8

\section{PUBLISHER}

(c) Taylor \& Francis/Routledge

\section{VERSION}

AM (Accepted Manuscript)

\section{PUBLISHER STATEMENT}

This work is made available according to the conditions of the Creative Commons Attribution-NonCommercialNoDerivatives 4.0 International (CC BY-NC-ND 4.0) licence. Full details of this licence are available at: https://creativecommons.org/licenses/by-nc-nd/4.0/

\section{LICENCE}

CC BY-NC-ND 4.0

\section{REPOSITORY RECORD}

Summerskill, Steve, Russell Marshall, Diane E. Gyi, J. Mark Porter, Keith Case, Ruth Sims, and Peter M. Davis. 2019. "Validation of the HADRIAN System with a Train Station Design Case Study". figshare. https://hdl.handle.net/2134/26650. 
In P. D. Bust (Ed.), 'Contemporary Ergonomics 2009'

Proceedings of the Annual Conference of the Ergonomics Society, 2009

(pp. 70-78). London: Taylor \& Francis. doi: $\underline{10.1201 / 9780203872512 . c h 8}$

\title{
VALIDATION OF THE HADRIAN SYSTEM WITH A TRAIN STATION DESIGN CASE STUDY
}

\author{
S.J. Summerskill ${ }^{a}$, R. Marshall ${ }^{a}$, D.E. Gyi ${ }^{\text {c }}$, J.M. Porter $^{a}$, K. Case ${ }^{\text {b }}$, R.E. \\ Sims $^{a}$ and P. Davis ${ }^{a}$ \\ ${ }^{a}$ Department of Design and Technology, ${ }^{b}$ Department of Mechanical and \\ Manufacturing Engineering, ${ }^{c}$ Department of Human Sciences, Loughborough \\ University, Loughborough, UK
}

\begin{abstract}
The HADRIAN (Human Anthropometric Data Requirements Investigation \& Analysis) human modelling system is under development at Loughborough University as part of the EPSRC funded AUNT-SUE (Accessibility and User Needs in Transport for Sustainable Urban Environments) project. The HADRIAN system aims to foster a 'design for all' ethos by allowing ergonomists and designers to see the effects of different kinds of disability on the physical capabilities of elderly and disabled people. This system is based upon the long established SAMMIE system (System for Aiding Man Machine Interaction Evaluation), and uses data collected from 102 elderly and disabled individuals (Joint range of motion and anthropometry, ability to use steps and stairs, lifts escalators etc.). The HADRIAN system allows three dimensional CAD data of new products to be imported, with subsequent analysis using all of 102 sample members. The 102 sample includes a stature range of $1^{\text {st }} \%$ UK female to $99^{\text {th }} \%$ ile UK male, and also includes a range of disabilities that have been assessed using scales from Martin et al (1994). In this way the needs of people with specific conditions, such as arthritis, can be demonstrated and where possible, design accommodation can be improved. This paper describes the validation activity that is underway with the HADRIAN system. The validation reflects the transport focus of the AUNT SUE project by using HADRIAN to analyse the user interaction points that people encounter when using the Docklands Light Railway in London. This includes the use of ticket machines, the use of the train station infrastructure such as lifts and steps and stairs, and the use of ATMs to obtain cash. The validation is being performed by comparing the predicted results from HADRIAN and the abilities of users when performing real life tasks such as retrieving a ticket from a machine, or pressing a floor button when in a lift.
\end{abstract}

\section{Introduction}

Human modelling systems (HMS) such as JACK, RAMSIS, SAMMIE (Porter et al 2004), and SAFEWORK are used in the design of vehicles, manufacturing environments and workstations. These systems use Computer Aided Design software to represent the 


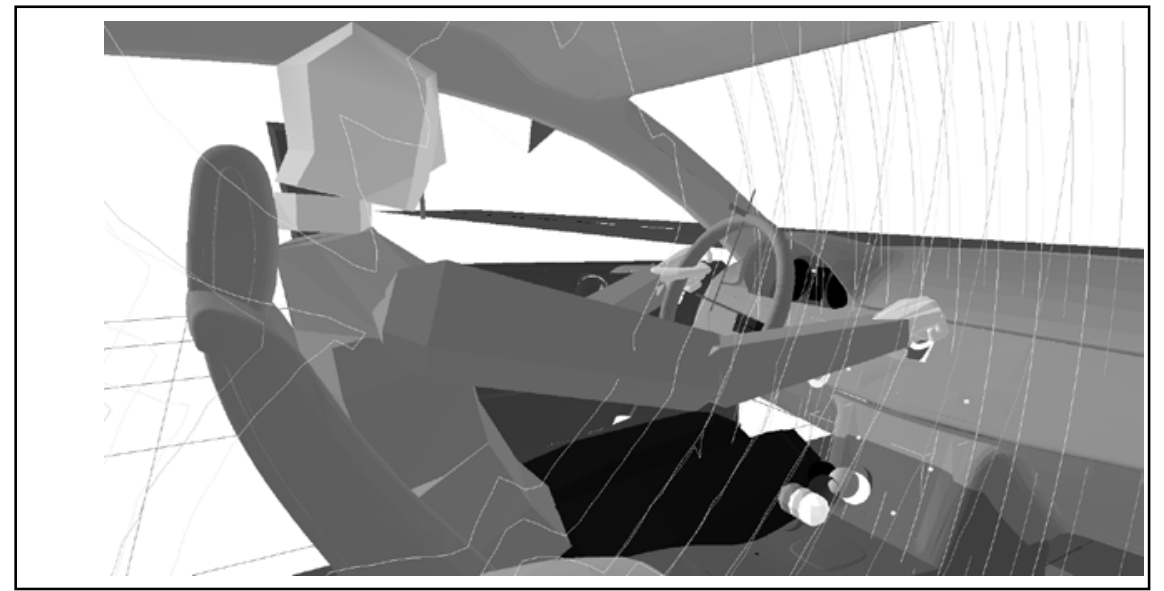

Figure 1. The use of SAMMIE in the design of an automobile interior (2007)

size and shape variability of humans in simulations of environments such as car interiors (see Figure 1). The ability to simulate how people of different sizes and nationalities are accommodated by a product removes the need for costly early physical prototypes. If used correctly within a design process that includes later prototypes that verify the HMS analysis results, HMS can be highly cost effective. Currently HMS systems support design activity with a focus on able bodied people. The aging population in the UK (WHO 2008) and a greater awareness of the needs of disabled people (Disability Discrimination Act (DDA 2005)), have raised the prospect of using HMS to simulate the effects of disability, supporting the design of more inclusive products. Using human modelling systems to represent the effects of disability does raise issues in terms of the expertise of the end user. The designers and engineers that use HMS in the product design process generally have little experience of the effects of disability or the coping strategies used by disabled people. Current HMS systems have no methods of representing the coping strategies used by disabled people, such as sliding a kettle along a work surface instead of carrying it. This paper describes the validation of a new HMS system that has been designed to combine anthropometric, joint range of motion and behavioural data for a sample of disabled people. The aim of the new system is to foster a greater awareness of the effects of disability amongst designers and engineers, whilst providing a tool that supports a design process resulting in greater accommodation of the needs of elderly and disabled people. The test bed for the new system (HADRIAN) is the long established SAMMIE system (Marshall et al 2004).

\section{The HADRIAN system}

A key feature of the HADRIAN system is that the process of evaluating a product is automated, removing the product designer or engineer from key stages of the HMS process that require knowledge of the behaviour of disabled people. The HADRIAN system allows a product analysis to be performed on the basis of a task description 
provided by the software user. For example, if a ticket machine is to be evaluated, the user would import a CAD model of the ticket machine into the HADRIAN system and build a list of tasks to be performed. Example tasks for a ticket machine include the use of a control to select on screen options, and depositing money into the coin slot. The HADRIAN system can perform these interactions for all of the sample members built into it, using data on the coping strategies of each individual to automatically perform tasks such as the positioning of the virtual user, to allow the best reach to the various controls built into the product. The system can then identify which users were unable to complete certain task stages based upon their ability to reach and view the interaction points of a product. This allows design changes to be identified that can increase the accommodation of the product, such as lowering a control or changing a screen angle. The behavioural data that is used in HADRIAN was captured from the video recording of kitchen based activities of daily living performed by each participant. The system also contains demographic information such as the type of disability, age, sex and occupation.

\section{The HADRIAN sample of users}

HADRIAN is based upon data collected from a sample of 102 people, the majority of whom were registered as disabled, or had age related impaired mobility. The sample of elderly and disabled users participated in the following data collection activities; anthropometric data, joint range of motion data, reach range data, completion of a questionnaire detailing the use of different modes of public transport, and the collection of baseline data on the ability of the participants to perform kitchen based activities of daily living. Within the sample of 102 people 59 people have some form of impairment including: limb loss, asthma, blood conditions, cerebral palsy, epilepsy, head injuries, multiple sclerosis, arthritis, vision and hearing impairments, heart problems, paraplegia, Parkinson's disease, stroke, and dyslexia, amongst others. Of the 43 able bodied people 20 were aged over 60 and had undiagnosed or minor impairments associated with being older. The remaining participants provide baseline information on the capabilities of non disabled people. All of the sample members included in HADRIAN were capable of living independently. Each subject was assessed using a modified version of the OPCS sample frame (Martin et al 1994) to allow a comparison of the severity of disability exhibited by the HADRIAN sample to prevalence and severity of disability in the UK.

\section{Anthropometric data used in the HADRIAN subject simulations}

The following anthropometric measures were collected from each participant. Stature, Arm length, Upper arm length, Elbow-shoulder, Abdominal depth, Thigh depth, Kneehip length, Ankle-knee length, Ankle height, Foot length, Sitting height, Sitting shoulder height, hip-shoulder length, Chest height, Chest depth, Head height, Eye-top of head, Buttock-knee length , knee height, Shoulder breadth, Hip breadth, Hand length and Grip length. 


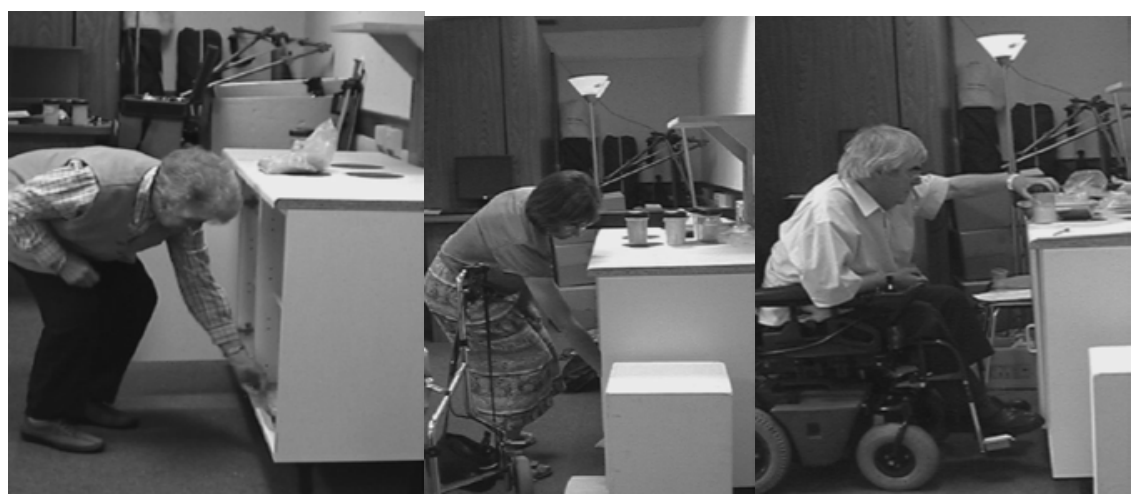

Figure 2. The postures adopted by participants when performing kitchen based tasks

\section{Joint Constraint data used in the HADRIAN subject simulations}

The following joint constraint data measures were collected from each participant; shoulder extension, shoulder flexion, shoulder abduction, shoulder adduction, arm extension, arm flexion, arm abduction, arm adduction, arm medial rotation, arm lateral rotation, elbow extension, elbow flexion, elbow pronation, elbow supanation, wrist extension, wrist flexion, wrist abduction, and wrist adduction.

\section{Data collected on positioning and posture}

The prototype version of HADRIAN contains automation data based upon the kitchen tasks that were performed in the user trials. The participants were asked to move a variety of objects onto a high shelf, a work surface, and into cupboards and shelves of standard kitchen units. This process was video recorded to allow the postures that were adopted to be coded (see Figure 2). Table 1 shows the positioning and postural data that were captured for both ambulant and wheelchair using participants. These coded data were used to inform the behavioural aspects of the HADRIAN task automation. A more detailed description of the HADRIAN system can be found in Marshall et al (2009).

\section{The Validation of the HADRIAN system}

The HADRIAN validation process aims to verify and potentially improve the data that drives the automation of the product assessment process. This is done by comparing the results of the analysis of the accessibility of three travel interaction points, namely, a ticket machine, a lift at a railway station 
Table 1. The coding information used to classify the postures exhibited by the HADRIAN sample members during the kitchen tasks

\begin{tabular}{|c|c|}
\hline $\begin{array}{l}\text { Postures and orientations to be } \\
\text { coded }\end{array}$ & Coding criteria for use in HADRIAN \\
\hline $\begin{array}{l}\text { Orientation of the user to the } \\
\text { kitchen cupboards }\end{array}$ & Face on, side on, angled approach \\
\hline Arm used for the tasks & Left or right \\
\hline $\begin{array}{l}\text { The posture of the legs during the } \\
\text { kitchen tasks (ambulant } \\
\text { participants only) }\end{array}$ & $\begin{array}{l}\text { Straight, bent } 1\left(\text { knee angle } 170-120^{\circ}\right) \text {, bent } \\
2\left(\text { knee angle } 119-40^{\circ}\right) \text {, crouch (knee angle } \\
\left.39-0^{\circ}\right) \text {, left kneel, right kneel, full kneel, } \\
\text { sitting }\end{array}$ \\
\hline Back twist & Left or right $>10^{\circ}$ \\
\hline Back bend & Upright $\left(0-10^{\circ}\right)$, lean $\left(11-45^{\circ}\right)$, bend $\left(46^{\circ}+\right)$ \\
\hline Shoulder & Relaxed, extended \\
\hline Head orientation & $\begin{array}{l}\text { Yaw (neutral, left, right }+/->10^{\circ} \text { ) Pitch } \\
\text { (neutral, forward back }+/->10^{\circ} \text { ) Tilt } \\
\text { (Neutral, left, right, }+/->10^{\circ} \text { ) }\end{array}$ \\
\hline
\end{tabular}

and an ATM machine. The selection of travel interaction points reflects the aim of the AUNT SUE project, which is to reduce social exclusion by supporting increased accessibility to the travel infrastructure by elderly and disabled people. Three different analysis techniques are used to assess the interaction points. Firstly an expert user of HMS, with extensive experience of the coping strategies used by disabled people, performed an analysis using HADRIAN data in SAMMIE. The SAMMIE system allowed the expert HMS user to simulate the anthropometry and joint range of motion only, with the experience of the expert user driving the behavioural aspects of the product analysis. The second analysis technique involves the use of the HADRIAN system to perform an automated analysis. Finally, a selection of the HADRIAN sample are asked to perform the same product interactions that were performed by their virtual counterparts with the real products. This has the potential to illustrate unexpected coping strategies or task failures that were not anticipated in the virtual user trials performed in SAMMIE and HADRIAN. Any new information gained regarding user behaviour can then be applied to refine the automation of HADRIAN for specific tasks.

\section{Validation sample members}

Ten HADRIAN subjects will participate in the validation process. The subjects selected were two people over 65 with arthritis (male and female), an ambulant disabled female with cerebral palsy who uses a wheeled walking frame, a male mobility scooter user with mobility problems caused by a brain tumour, a powered wheelchair user with limited strength in the right arm due to a stroke, and five manual wheelchair users with a range of upper body mobility. These participants exhibit physical limitations in joint range of motion and reaching ability that affect their ability to interact with products, which can be compared between the three analysis techniques. 

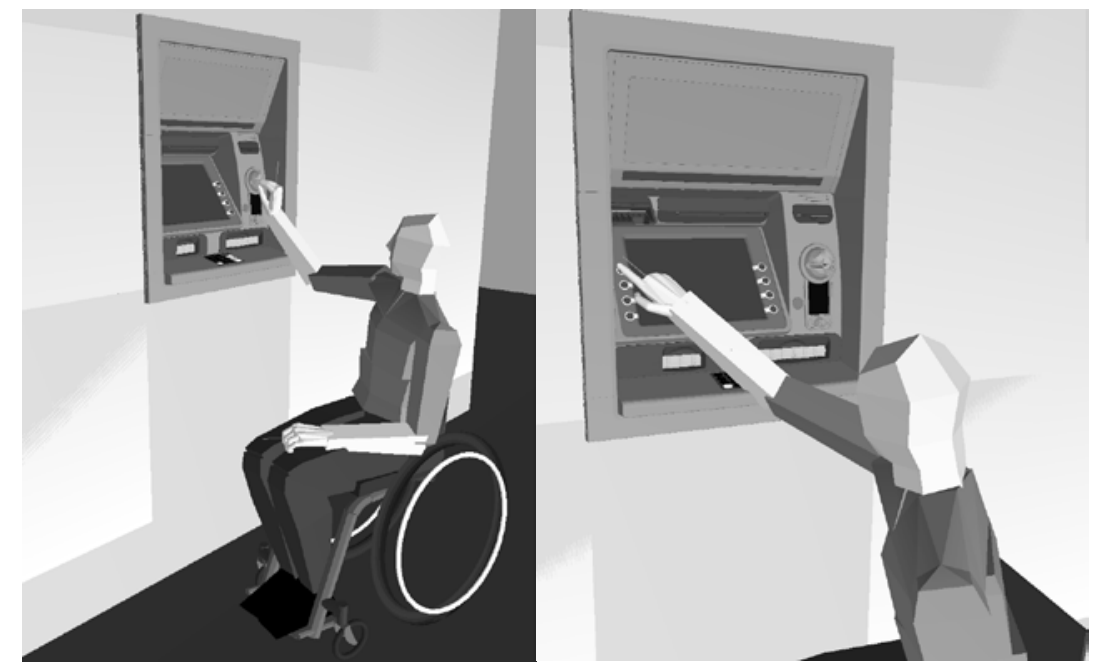

Figure 3. The analysis of an NCR ATM design with a paraplegic participant with good upper body mobility.

\section{Validation progress}

The analysis of the lift, ticket machine and ATM has been performed by the expert user with the sample of ten HADRIAN participants. Figures 3, 4 and 5 show the analysis in progress for the ATM, ticket machine and lift respectively.

The analysis of two NCR ATM designs

The cash machine manufacturer and project collaborator NCR has provided two cash machine designs for the validation process. This includes real ATM fascias for an analysis using the HADRIAN sample members, and CAD data to allow a virtual analysis using HADRIAN and SAMMIE as shown in Figure 3. The ATM illustrated in Figure 3 is a new design that is currently being installed world wide. An earlier model has also been provided by NCR. The analysis of the ATM involves different mounting heights for the ATM, the range of which is found internationally. Each HADRIAN participant will be asked to perform typical product interaction stages (insert a credit card, select a cash withdrawal by using a screen button, collect the cash, deposit a cheque in an envelope) which have been reproduced using the virtual analysis techniques.

The analysis of the ticket machine used by the Docklands Light Railway (DLR) in London

The analysis of the ticket machines used by the DLR will be performed using a sample of participants based in the London area. These participants have been matched to 


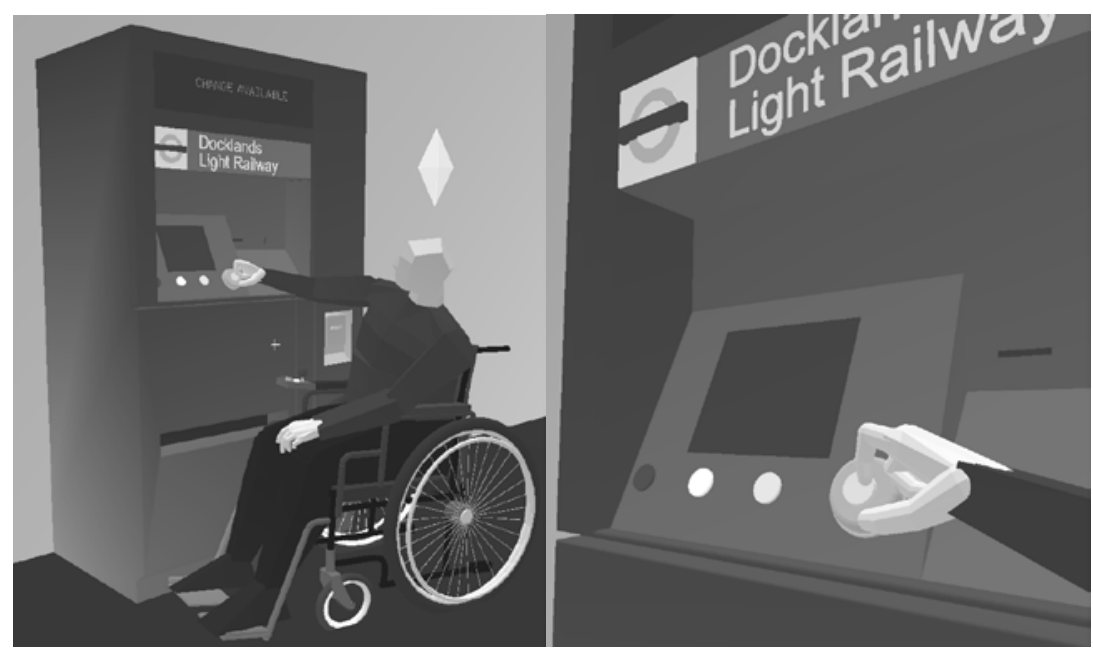

Figure 4. The analysis of the ticket machine used in DLR stations in London with a participant that has limited mobility due to a stroke

members of the original sample in terms of their type and severity of disability. This allows an analysis of the general applicability of the design recommendations made using the original HADRIAN sample members, when compared to other people with similar conditions. For example, the participant shown in Figure 4 exhibits limited shoulder rotation and arm strength due to a combination of a broken back suffered in a car accident and a subsequent stroke. This meant that the joint constraints applied to the human model in SAMMIE and HADRIAN indicated difficulty in reaching to the controls and coin slot incorporated in the design. This necessitated a near sideways approach by this wheelchair user which allowed the virtual participant to reach all of the interaction points, but also caused a poor viewing angle to the screen. The completed virtual analysis determined that the user would find it difficult to read the on screen information. The comparison between the virtual results and those of the real participants will be the basis for the validation HADRIAN data for this product. The virtual analysis has been completed in both the HADRIAN and SAMMIE systems, providing a range of design recommendations that would improve the accommodation of the device for use by elderly and disabled people, whilst not disadvantaging non disabled users. The next stage of the validation process will be the matched sample user trials in London, which will follow a scenario that includes the use of the ticket machine, accessing the platform level using the lift or a ramp that is over $100 \mathrm{~m}$ long, boarding a train and then returning to the original station. The DLR station is due for refurbishment. The DLR management have supported the validation process by providing CAD data for ticket machines and access to the Greenwich station for measurement and assessment activities. The design recommendations produced by the validation process will be considered by the DLR management for inclusion in the refurbishment of the Greenwich DLR station.

\section{The analysis of a lift used in the DLR train station in Greenwich, London}

The analysis of the lift used in the DLR train station will follow the matched sample approach used in the analysis of the DLR ticket machine. The virtual analysis of the lift 


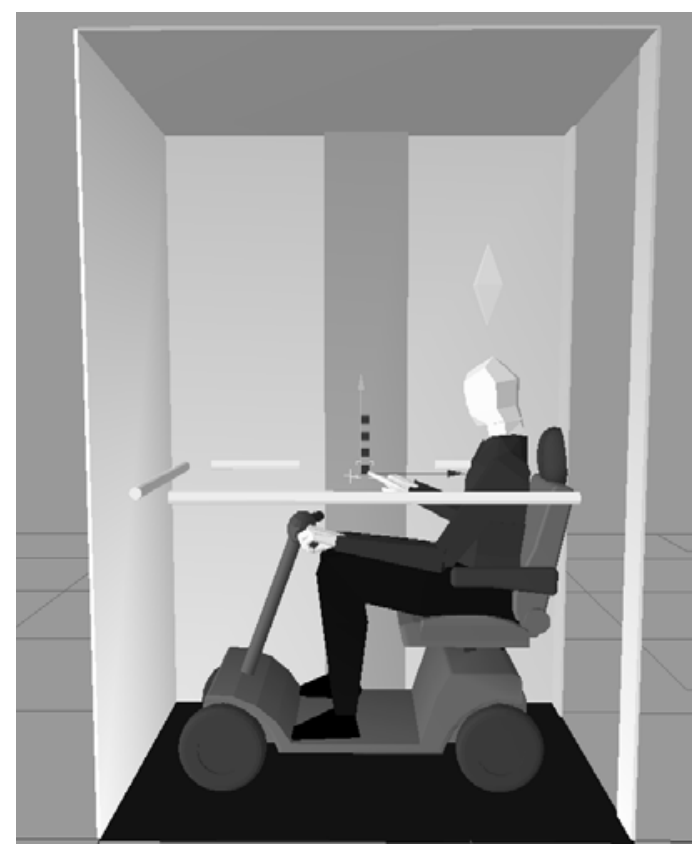

Figure 5. The analysis of a lift found at the Greenwich Docklands Light Railway (DLR) station in London with a participant with mobility problems caused by a brain tumour

has indicated a number of design recommendations. The virtual evaluation shown in Figure 5 indicated that a mobility scooter user would be unable to share the lift with other users due to space constraints. Also, the limited mobility of the user indicated difficulty in looking backwards when reversing the mobility scooter out of the lift (the user had removed the mirrors usually attached to the mobility scooter). Other HADRIAN sample members indicated that the limited width of the lift would make it difficult for people with limited upper body mobility to access the buttons for the alarm and holding the doors open, as these were located in the highest location on the control panel.

The matched sample that will be asked to use this lift at the Greenwich DLR station will be observed to determine if these issues arise.

\section{Conclusions}

The HADRIAN validation process has been designed to verify and improve the automation of the HMS analysis of products that are associated with the travel infrastructure. The virtual analysis that has been completed has highlighted access issues that could hinder the use of public transport systems by people with disabilities and older people. The verification of these results with real users will demonstrate the effectiveness of the HADRIAN system for the analysis of tasks which are different to 
those upon which the automation is based, i.e. kitchen based tasks. Any differences in the assumed behaviour of the virtual HADRIAN sample members that are found in reality, will serve to fine tune the automation of the HADRIAN system. The dissemination of the HADRIAN dataset will take three forms. The first form will be a database that presents the information gathered to researchers and designers. The second form will be data which can be applied to all current HMS systems in terms of anthropometry and joint range of motion, and the third form will be HADRIAN itself, which will combine all of the data available with automation of the product analysis. The use of HADRIAN has the potential to support designers and ergonomists in their efforts to improve access for disabled people who have the capability to live independently, but who are excluded from public transport use by an infrastructure design process that does not currently take account of their needs.

\section{References}

Disability Discrimination Act 2005 [online]. Office of Public Sector Information. Available from: http://www.opsi.gov.uk/acts/acts2005/ukpga_20050013_en_1

Marshall, R., Case, K., Porter, J.M., Sims, R.E. and Gyi, D.E., 2004. Using HADRIAN for Eliciting Virtual User Feedback in 'Design for All', Journal of Engineering Manufacture; Proceedings of the Institution of Mechanical Engineers, Part B, 218(9), 1st September 2004, 1203-1210

Marshall, R, Summerskill, S.J., Gyi, D.E., Porter, J.M., Case, K., Sims, R.E. and Davis, P., 2009. A design ergonomics approach to accessibility and user needs in transport. In: Contemporary Ergonomics 2009, proceedings of the Annual Conference of the Ergonomics Society. London, UK, April 2009.

Martin, J., Meltzer, H. and Elliot, D., 1994. OPCS surveys of disability in Great Britain: The prevalence of disability among adults, London: HMSO.

Porter, J.M., Marshall, R., Freer, M. and Case, K., 2004. SAMMIE: a computer aided ergonomics design tool. In: N.J. Delleman, C.M. Haslegrave, and D.B. Chaffin eds. Working Postures and Movements - tools for evaluation and engineering. Boca Raton: CRC Press LLC, 454-462.

WHO, 2008. WHO Ageing [online]. World Health Organisation. Available from: http://www.who.int/topics/ageing/en/ [Accessed 01/09/2008]. 